\title{
STUDIES ON PLANT BILE PIGMENTS - 6. PHOTOCHEMICALLY ASSISTED REACTION OF A-DIHYDROBILINDIONE WITH NUCLEOPHILES AS A MODEL FOR PHYTOCHROME INTERCONVERSION
}

\author{
C. KRauss, C. Bubenzer and H. SCheER* \\ Botanisches Institut, München, W. Germany
}

(Received 23 February 1979; accepted 1 May 1979)

\begin{abstract}
From the A-dihydrobilindione 3, the pyridinium derivatives $6 \mathbf{a}, \mathbf{b}$ and analogues their of have been obtained by a formal nucleophilic substitution. The reaction is rationalized as a photochemically assisted oxidation of 3 with a subsequent regioselective addition of pyridine at C-5. By thermolysis. 6a.b yields back the parent bilin 3, together with an oxidation product. The significance of the reaction with respect to the phytochrome interconversion is discussed.
\end{abstract}

\section{INTRODUCTION}

Phytochrome, the photomorphogenetic reaction center pigment of higher green plants and some algae, contains a bile pigment chromophore covalently linked to the protein (Siegelman et al., 1966; Rüdiger, 1975). The photochromic conversion between the two long-lived forms $\mathrm{P}_{\mathrm{r}}$ and $\mathrm{P}_{\mathrm{rr}}$ is the primary event of the photomorphogenetic reaction chain (Pratt, 1978; Briggs and Rice, 1972). Pr contains the A-dihydrobilindione chromophore 1 (Klein and Rüdiger, 1978, Schoch et al., 1976; Klein et al., 1977; Grombein et al., 1975; Scheer, 1976). For the chromophore of $P_{i r}$, structure 2 with the $\beta$-pyrrolic side chains unaltered (Klein et al., 1977) and a chromophore no longer containing the $\Delta 4,5$-double bond (if judged from UV-vis spectra, Grombein et al., 1975) has been proposed. This proposal implies a change in the molecular structure during the $\mathrm{P}_{\mathrm{r}} \rightleftarrows \mathrm{P}_{\mathrm{fr}}$ interconversion and excludes conformational changes and/or protonationdeprotonation events as the sole structural difference between the two forms (see Scheer, 1978, for a discussion).

In exploiting the synthetic bilin 3 as a model for 1 , an increased reactivity at the $\Delta 4,5$-double bond has been characterized for A-dihydrobilindiones, as compared to their fully unsaturated analogues, e.g. 7 (Scheer and Krauss, 1977; Scheer et al., 1977). Specifically, the reversible photodimerization of 3 has been proposed as a model type reaction for the phytochrome interconversions (Scheer and Kraus, 1977). Since present evidence supports but one chromophore in the monomeric phytochrome (Pratt 1978; Briggs and Rice, 1972; and citations therein), the possibility of using partners other than a second bilin for addition reactions has been studied. Here, we report the

* Reprint requests should be sent to: Dr. Hugo Scheer, Botanisches Institut, Menzinger Str. 67, 8000 München 19. W. Germany.

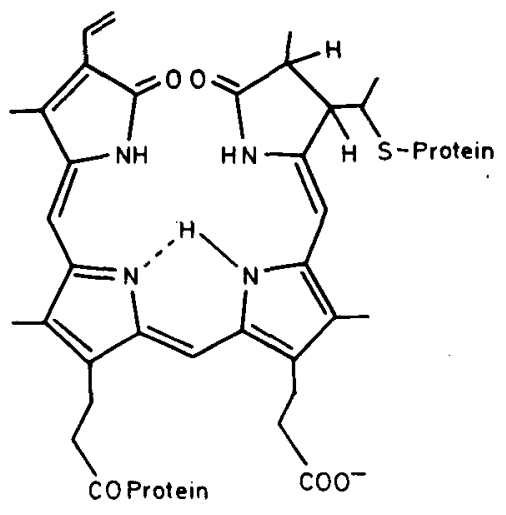

I

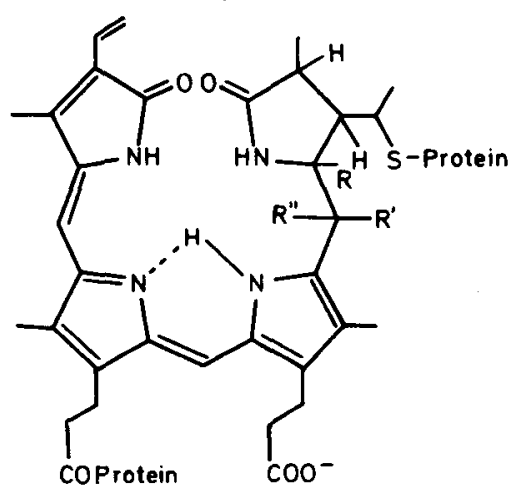

2

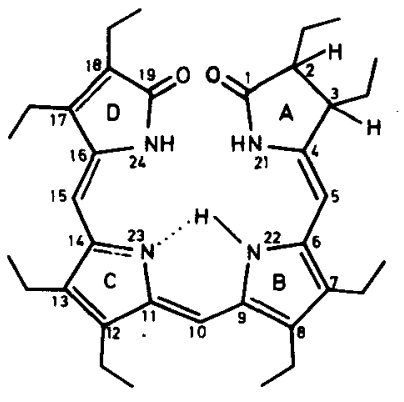

3 
<smiles>CCC1=C(CC)C(/C=C2\NC(=O)C(CC)=C2CC)=[N+]2[CH]n3c(c(CC)c(CC)c3/C=C3\NC(=O)C(CC)=C3CC)C=C12</smiles>

7<smiles>[R]C([R])([R])c1ccc2n1[CH][N+]1=C(C=C3C=CC(=O)N3)C=CC1=C2</smiles>

8

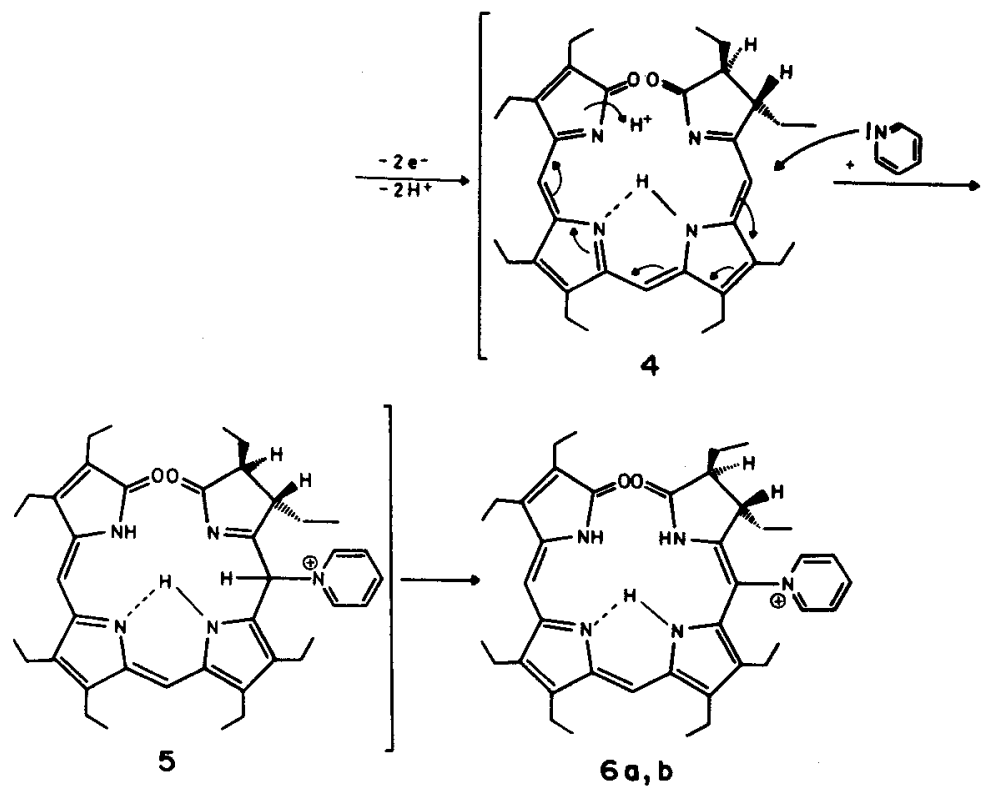

Reaction scheme

reversible, photochemically assisted addition of nucleophiles of the pyridine type.

\section{MATERIALS AND METHODS}

The A-dihydrobilindione 3 was prepared by the method of Cavaleiro and Smith (1973) from octaethylporphyrin via octaethylchlorin (Whitlock et al., 1969). $I_{2}$ and pyridine were reagent grade, the latter was dried over basic alumina (Woelm-ICN. Eschwege). All solvents were destilled prior to use or were reagent grade. Preparative photochemical reactions were carried out under nitrogen in pyrex cylinders at starting concentrations $c=0.1 \mathrm{mM}$ of compound 3 with the light of a $1000 \mathrm{~W}$ tungsten halogen source $\left(13 \mathrm{~W} / \mathrm{m}^{2}\right.$ between 550 and $\left.620 \mathrm{~nm}\right)$. UV-vis absorption spectra were recorded on a DMR 22 spectrophotometer (Zeiss, Oberkochen), and are reported in the format $\lambda_{\max }[\mathrm{nm}]\left(\epsilon \cdot 10^{-3}\right)$. Mass spectra were obtained in the EI mode with a JMS-D 100 spectrometer (Jeol, Japan), and in the FD mode with a model 731 instrument (VarianMAT, Bremen). 'HMR spectra were recorded in the FT mode on a HFX 90 instrument (Bruker, Karlsruhe) with
$\left(\mathrm{CH}_{3}\right)_{4} \mathrm{Si}$ as internal standard. Chemical shifts are reported in $\delta[\mathrm{ppm}]$. Column chromatography of the reaction mixtures was carried out by an improved HPLC method (Schoch et al., 1978) on silica with a slightly alcaline ternary eluent system. For TLC, silica H (Merck, Darmstadt) was used.

\section{RESULTS AND DISCUSSION}

Irradiation of 3 in benzene/pyridine $(4: 1)$ in the presence of $\mathrm{I}_{2}$ or other one-electron oxidants leads to a rapid colour change from blue to violet, similar to the change occurring during dimerization in the absence of pyridine (Scheer and Krauss, 1977) (Fig. 1). Chromatography of the product mixture yields only traces of the dimers, however. Two main products can be isolated, which migrate on silica only at high methanol concentrations, and which are irreversibly adsorbed upon prolonged exposure to silica. TLC: $\mathbf{R}_{\mathbf{r}}=0.52$ and 0.62 , respectively, in dichloromethane/ methanol $=9: 1$, containing $1 \%$ aqueous ammonia; 


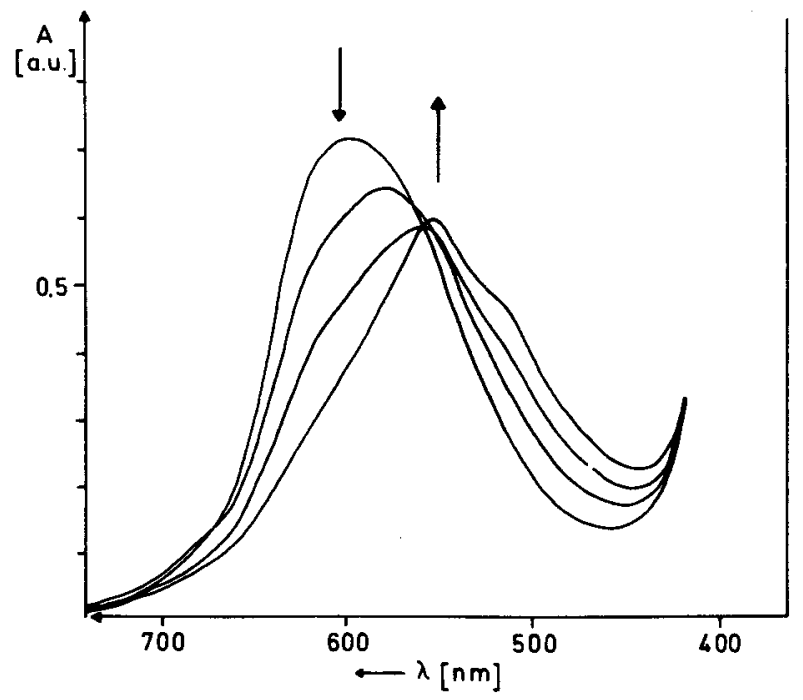

Figure 1. UV-vis spectra of the photochemical reaction of $3(40 \mu M)$ in benzene containing pyridine $(2.47 \mathrm{M})$ and $\mathrm{I}_{2}(19.0 \mu \mathrm{M})$. Each trace corresponds to $1 \mathrm{~min}$ irradiation time, for the light conditions, see text. The arrows denote the change of absorption during the reaction.

HPLC: $V_{R}=106$ and $182 \mathrm{~m} /$, respectively, on $4 \times$ $300 \mathrm{~mm}$ silica with dichloromethane $/$ methanol $=$ $1: 1$ containing $0.04 \%$ aqueous ammonia as eluent. The two products are interconvertible, e.g. by acid, and thus assigned as isomers. From the slower migrating zone, the isomer $6 \mathbf{a}$ of 2,3-dihydro-5(1-pyridinium)-octaäthyl-1,19(21,24H)-bilindione has been isolated, the faster migration zone contains $\mathbf{6 b}$.

$U V$-vis (see also Fig. 2): Cation (corresponding to the chromophore free base): 545 (10.27), 326 (19.9); dication (corresponding to the chromophore monocation): 603 (25.5), 327 (21.4); zwitterion (corresponding to the chromophore anion): 585 (9.7); zinc complex: 630 (17.5), 585 (9.7), $330(25.5)$

${ }^{1} \mathrm{HMR}: \mathrm{C}^{2} \mathrm{HCl}_{3}$ : 6a: 6.72 (H-10, s), 5.92 (H-15, s), 8.21 (Pyr-H-B,B', 'd'), 8.49 (Pyr-H-A, 't'), 9.04 (Pyr-H-C,C', ‘d'). 6b: 6.76 (H-10, s) 5.96 (H-15, s) 8.29 (Pyr-H-B,B', 'd'). 8.70 (Pyr-H-A, 't') 9.38 (Pyr-H-C, C', 'd'). $\left(\mathrm{C}^{2} \mathrm{H}_{3}\right)_{2} \mathrm{CO}: 6 \mathrm{a}: 7.07$ (H-10 s), 6.21 (H-15, s), 8.42 (Pyr-H-B,B', 'd'), 8.92 Pyr-H-A, 't'), 9.59 (Pyr-H-C,C', 'd'). 6 b: 7.04 (H-10, s), 6.18 (H-15, s), 8.50 (Pyr-H-B,B'. 'd'), 8.94 (Pyr-H-A. 't'), 9.57 (Pyr-H-C,C' 'd'). $\mathrm{CF}_{3} \mathrm{COO}^{2} \mathrm{H}:$ 6a: $7.71^{\circ}$ (H-10, s), 6.60 (H-15, s), 8.35 (Pyr-H-B,B', 'd'), 8.70 (Pyr-H-A, 't'), 9.11 (Pyr-H-C,C',

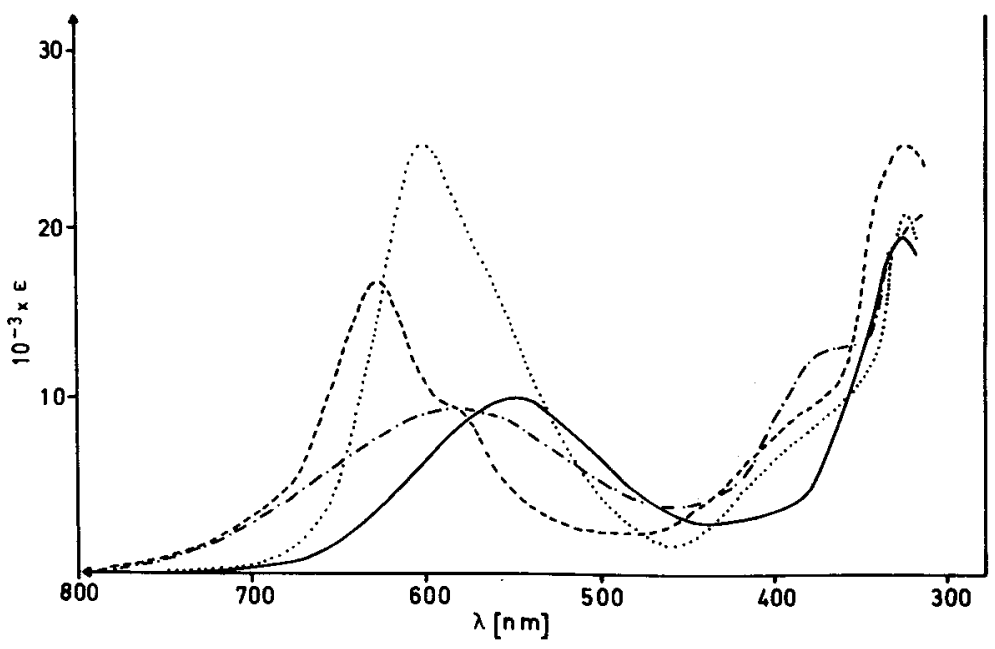

Figure 2. UV-vis spectra of the pyridinium salt $6 \mathbf{a}$ in methanol (-), its protonated form obtained after addition of $0.25 \%$ of $35 \% \mathrm{HCl}(\cdots)$, its deprotonated form obtained after addition of $0.25^{\circ}$. methanolic $\mathrm{KOH}(-.--)$, and its $\mathrm{Zn}$-complex obtained after addition of $0.25^{\circ}$ saturated methanolic $\mathrm{Zn}$-acetate (-...). Extinction coefficients are based on the assumption of $\mathrm{OH}^{-}$as counterion after silica chromatography. 
'd'). 6b: 7.68 (H-10, s), 6.48 (H-15, s), 8.43 (Pyr-H-B,B', 'd'), 8.80 (Pyr-H-A, 't'), 9.29 (Pyr-H-C,C', 'd').

MS:EI-Mode: $556(100 \%), 554$ (66\%), 527 (46\%), $432(45 \%), 421(24 \%), 418(26 \%) . \quad F D-M o d e: 634$ $(100 \%), 556(6 \%)$.

Structure 6 of the pyridinium adducts has been established by the following arguments: (1) The 'HMR spectrum shows the $\mathrm{ABB}^{\prime} \mathrm{CC}^{\prime}$ pattern (two 'doublets' and one 'triplet' ( $J_{\text {:ppurem }} \approx 7 \mathrm{~Hz}$ ) in the ratio $2: 2: 1)$ and the chemical shifts typical for $N$-substituted pyridinium ions (Abramovitch. 1974; Diner and Lown, 1971): (2) The FD mass spectrum has a peak at the highest mass of $634 \mathrm{~m} / \mathrm{e}$ (base peak), the only major fragment occurs at 556/e. In the El spectrum, there are no reproducible peaks above the basis peak at $556 \mathrm{~m} / \mathrm{e}$; (3) The chromatographic properties indicate an ionic compound; (4) The site of substitution is indicated from the ${ }^{1} \mathrm{HMR}$ spectrum. Of the three methine resonances in 3 assigned to $\mathrm{H}-5$ (5.44 ppm), H-10 (6.56 ppm) and H-15 (5.97 ppm) (Cavaleiro and Smith, 1973), the ones of H-15 and $\mathrm{H}-10$ are slightly shifted, but still present in $6 \mathbf{6}$ and 6b while the high-field signal characteristic for $\mathrm{H}-5$ is lacking; (5) The UV-vis spectra (Fig. 2) of the monocation, dication, zwitterion and zinc complex are in the wavelength ranges typical of the free bases, cations, anions and zinc complexes, respectively, of 'biliviolins' containing the tripyrrinone chromophore

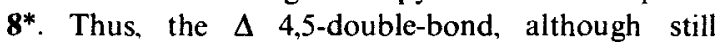
present, is spectroscopically no longer evident. This effect of large meso-substituents has been observed earlier by Bonfiglio et al. (1977) and related to the uncoupling of the adjacent rings by a pronounced twist between them; (6) The hydrogenated ring $A$ is still present, as evidenced by the characteristic ${ }^{1} \mathrm{HMR}$ multiplet (Scheer et al., 1977) at $\delta=1,5-1,8 \mathrm{ppm}$ $\left(2^{\prime}, 3^{\prime}-\mathrm{CH}_{2}\right)$, by the $556 \mathrm{~m} / \mathrm{e}$ peak in the mass spectra. and by the reversion experiments; (7) The product is formulated as the tautomer 6 rather than 5 for the lack of a third meso proton signal in the ${ }^{1} \mathrm{HMR}$ spectrum, and for the generally higher basicity of $\mathrm{N}$ as compared to $C$.

Due to its ready interconversion, compound $6 \mathbf{a}$ contained $19 \% 6 \mathrm{~b}$. In addition to the thermal disproportionation (see below), this is another reason for us not being able to obtain a defined melting point. The isomer mixture $\mathbf{6 a , b}$ can be analyzed by ${ }^{1} \mathrm{HMR}$. The signals of the methine protons and of the pyridinium ring protons listed above are most suitable due to their large separation for the respective isomers, but doubling of some signals can even be

\footnotetext{
*The term 'violin' is used here as a phenomenological description designating linear oligopyrroles with a single visible absorption band of the free base around $560 \mathrm{~nm}$. Formula 8 with $R_{1}, R_{2}, R_{3} \neq 0$ is typical of these compounds. Historically, the term has been associated with 4.5-dihydro-1,19 $(21,24 \mathrm{H})$ bilindiones.

tThe central methine bridge $(C-10)$ is the principal point of nucleophilic attack in the (unoxidized) free bilins both for bilindiones (Falk and Schlederer, 1978; Holzwarth et al., 1978) and dihydrobilindiones (Kufer and Scheer, 1979).
}

observed in the methyl- and methylene region. After equilibration in $\mathrm{CF}_{3} \mathrm{COO}^{2} \mathrm{H}$, the isomer ratio $\mathbf{6 a}: \mathbf{6 b}=2: 1$ has been obtained, as compared to $4,5: 1$ in the reaction mixture.

The stereochemical origin for 6 to occur as isomers can be related to steric hindrance of the meso-pyridinium and the $\beta$-pyrrolic substituents. By this means, rotation around the C-5, C-6 bond is hindered, leading to atropisomers. In conjunction with the asymmetric centers at ring A (transoid configuration of the ethyl groups), this gives rise to two diastereomeric pairs of enantiomers, even in case of the rings $B, C$ and $\mathrm{D}$ being coplanar. Based on this model, the 5-nitrobilindione obtained from an achiral bilindione (Bonfiglio et al., 1973) possibly is a racemate.

Reaction $3 \rightarrow 6$ is formally a nucleophilic substitution at C-5. It can be rationalized by the sequence shown in Scheme 1. Electron abstraction by the oxidant and subsequent deprotonation by the base present leads to a radical, and by repetition to the hypothetical dehydrobilindione 4, either one of which is attacked by pyridine at C-5 to yield 6 after tautomerization. Accordingly, the reaction is facilitated with the 2,4, 2,6 and 3,5-lutidines due to the inductive effect of the alkyl groups, and by increasing concentrations of the oxidant, $I_{2}$. Nucleophilic attack on cation radicals or dications of fully unsaturated bilindiones have been reported to occur at both the outer methine bridges (Eivazi et al., 1977). Although we have not yet identified all by-products of the reaction of 3 , the predominant formation of $\mathbf{6 a , b}$ supports again (Scheer, 1978), that hydrogenation of ring $A$ activates selectively the adjacent methine bridge under oxidizing conditions.t Formation of $\mathbf{6 a , b}$ is photochemically assisted, but occurs principally in the dark, too. An anaerobic solution of $3(40 \mu M)$ in benzene containing $\mathrm{I}_{2}(7.75 \mu \mathrm{M})$ and pyridine $(2.47 \mathrm{M})$ has been quenched after $2 \mathrm{~h}$ standing in the dark by filtration over $\mathrm{Na}_{2} \mathrm{~S}_{2} \mathrm{O}_{3}$ into glycine buffer ( $\mathrm{pH} 2.7$ ). After workup, it contained $5 \%$ of the isomers 6 a,b (in addition to minor amounts of a dimeric violin), besides unaltered 3 . The dark reaction is accompanied by a slight blue-shift of the absorption spectrum. which indicates the formation of an intermediate. The educt 3 can be recovered in high yield from this intermediate, but the latter is an activated form of 3 which forms rapidly 5-oxobilindiones and formyltripyrrionones (Scheer et al., 1977) upon addition of $\mathrm{Zn}^{2+}$ and admission of air. $A$ fresh solution of 3 with pyridine and $I_{2}$, in which the spectral changes are not yet visible, reacts at least an order of magnitude slower under otherwise identical conditions. At the present state, it is impossible to assign a specific structure (isomer, complex, or a more or less oxidized species) to this intermediate formed in the dark. As the photochemical reaction occurs rapidly even in freshly prepared solutions, the latter appears to be independent from the dark intermediate.

To account for the long-wavelength absorption of $\mathbf{P}_{\mathrm{f}}$, Grombein et al. (1975) have invoked the chromo- 
Table 1. Apparent $\mathrm{pK}$-values for protonation $\left(\mathrm{p} K_{1}\right)$ and deprotonation $\left(p K_{2}\right)$ of bile pigments. The values are determined by titration of the bilins $\left(c \approx 10^{-5} \mu M\right)$ with $\mathrm{HCl}$ and $\mathrm{KOH}$, respectively, in a $1: 1$ mixture of a saturated solution of guanidinium chloride in water and methanol (Scheer. 1976) monitored with a glass electrode

\begin{tabular}{lcc}
\hline Compound & $\mathrm{p} K_{1}$ & $\mathrm{p} K_{1}$ \\
\hline 3 & $5.6^{*}$ & $10-11 \dagger$ \\
7 & $5.1^{*}$ & $10-11 \dagger$ \\
Dimer of 3 & 1.4 & 11 \\
6a,b & 4.2 & 9.2
\end{tabular}

*From Scheer (1976).

†Destruction at $\mathrm{pH}>10$ during titration.

phore to be present in a deprotonated form. Based on this suggestion, a model for the $\mathrm{P}_{\mathrm{ir}}$ chromophore should not only have a violin-type absorption spectrum, but also a sufficiently low $\mathrm{p} K$-value to be deprotonated under physiological conditions. Violins generally have too high $\mathrm{p} K$-values in this respect (Falk and Leodolter, 1978), and this is true, too, for the dimeric violins. By contrast, the $\mathrm{pK}$ of $\mathbf{6 a , b}$ is considerably lower. Acid-base titrations of $\mathbf{6 a , b}$ in a mixed solvent system (Scheer, 1976) gave a poorly defined $\mathrm{pK}=9.1$ (Table 1) for the reversible deprotonation to the zwitterion (spectrum in Fig. 2). The $\mathrm{p} K$ decrease is rationalized by coulomb interactions, similar to, e.g. the $\mathrm{p} K$ decrease of the carboxyl group in amino acids.

Like the dimers described earlier (Scheer and
Krauss 1977), compound 6a,b reverts thermally to the educt 3. The reversion occurs already at lower temperatures, e.g. in the FD source of the mass spectrometer at $76^{\circ}$. If carried out on a micropreparative scale, 3 is accompanied by the bilindione 7 and another unidentified oxidation product of the violin type. In contrast to the cleavage of the dimers, the reversion reaction of $\mathbf{6 a , b}$ in the absence of an added reductant can only be accomplished by a disproportion reaction. This type of reaction has recently been indicated for the bilindione series, too (Eivazi et al., 1977). It should be noted in this context that the in vitro dark reversion of $\mathrm{P}_{\mathrm{fr}}$ to $\mathrm{P}_{\mathrm{r}}$ is accelerated by reducing agents (Mumford and Jenner, 1971; Kufer and Scheer, 1979).

If the principle of a photochemically assisted nucleophilic addition is applied to the phytochrome interconversion, one would expect the protein side chains of cysteine, tyrosine, histidine or tryptophane as the most likely reaction partners. Preliminary results with the respective $\mathrm{N}$ - and $\mathrm{C}$-protected amino acids have indicated that the latter three can add to compound 3, thus supporting this model.

Acknowledgements-This work was supported by a grant from the Deutsche Forschungsgemeinschaft Bonn-Bad Godesberg. We are indebted to the Münchner Universitätsgesellschaft for financial aid. We thank Prof. W. Rüdiger for helpful discussions and continuing support, Prof. H. Budzikiewicz (University, Köln) for providing the FD-mass spectra, and $G$. Schild for measurement of the ${ }^{1} \mathrm{HMR}$ spectra.

Note added in proof. In an attempt to identify intermediates of the oxidative reaction, a long-lived $\pi$-cation radical produced from the zinc complexes of $\mathbf{3}$ and $\mathbf{7}$ has recently been characterized (Krauss, C. and H. Scheer (1979) Tetrahedron Lett., in press).

\section{REFERENCES}

Abramovitch. A. (1974) Pyridine and its Derivates, Vol. 14. Suppl. pt 1. Interscience. New York. Bonfiglio, J. V.. R. Bonnett, M. B. Hursthouse, K. M. A. Malik and S. C. Naithani (1977) J. Chem. Soc. Chem. Commun. 829-830.

Briggs, W. R. and H. V. Rice (1972) Ann. Rev. Plant Physiol. 23, 293-334.

Cavaleiro. J. A. S. and K. M. Smith (1973) J. Chem. Soc. Perkin Trans. I 2149-2155.

Diner, U. E. and E. W. Lown (1971) Can. J. Chem. 49. 403-415.

Eivazi, F.. W. M. Lewis and K. M. Smith (1977) Tetrahedron Lett. 3083-3086.

Falk, H. and T. Schlederer (1978) Monatsh. Chem. 109, 1013-1015.

Falk, H. and A. Leodolter (1978) Monatsh. Chem. 109, 883-897.

Grombein, S., W. Rüdiger and H. Zimmermann (1975) Hoppe Seyler's Z. Physiol. Chem. 346. 1709-1714.

Holzwarth, A. R., H. Lehner, S. E. Braslavsky and K. Schaffner (1978) Liehigs Ann. Chem. 2002-2017.

Klein, G., S. Grombein and W. Rüdiger (1977) Hoppe Seyler's Z. Physiol. Chem. 358, 1077-1079.

Klein, G. and W. Rüdiger (1978) Liebigs Ann. Chem. 267-279.

Kufer, W. and H. Scheer (1979) Hoppe Seyler's Z. Physiol. Chem. 360, 935-956.

Mumford, F. E. and E. L. Jenner (1971) Biochemistry 10, 98-101.

Pratt, L. H. (1978) Photochem. Photobiol. 27, 81-105.

Rüdiger, W. (1975) Ber. Dt. Bot. Ges. 88, 125-139.

Scheer, H. (1976) Z. Naturforsch. C 31, 413-417.

Scheer, H. and C. Krauss (1977) Photochem. Photobiol. 25, 311-314.

Scheer, H., U. Linsenmeier and C. Krauss (1977) Hoppe Seyler's Z. Physiol. Chem. 358. 185-196,

Scheer, H. (1978) Proceedings of the European Meeting on Photomorphogenesis. Aarhus, 25-52.

Schoch, S., G. Klein, U. Linsenmeier and W. Rüdiger (1976) Liebigs Ann. Chem. 549-558.

Schoch, S., U. Lempert, H. Wieschhoff and H. Scheer (1978) J. Chromatogr. 157, 357-364.

Siegelman, H. W., B. C. Turner and S. B. Hendricks (1966) Plant Physiol. 41, 1289-1292.

Whitlock, H. W., Jr., R. Hanauer, M. Y. Oester and B. K. Bower (1969) J. Am. Chem. Soc. 91, 7485-7489. 